\title{
Contrasting the effectiveness of chloramines reduction in indoor swimming pools disinfected by Ozone versus UV
}

\author{
Iris Chan, Bobby Sidhu \\ ${ }^{1}$ Lead Author, B. Tech Student, School of Health Sciences, British Columbia Institute of \\ Technology, 3700 Willingdon Avenue, Burnaby, BC V5G 3H2 \\ ${ }^{2}$ Supervisor, School of Health Sciences, School of Health Sciences, British Columbia Institute of \\ Technology, 3700 Willingdon Avenue, Burnaby, BC V5G 3H2
}

\begin{abstract}
Objectives: Chloramines are disinfection by-products that are produced between chlorine and contaminants in the pool. Exposures to chloramines at high levels or for extended durations have been found to cause mucous membrane irritations and respiratory distress in humans. To reduce chloramines production, secondary treatment in the form of UV and ozone are used in newer indoor swimming pools. This study aimed to examine whether there is a difference between UV and ozone treatment in their effectiveness in reducing chloramines in indoor pools. Killarney leisure pool and whirlpool, which utilized ozone treatment, as well as Hillcrest leisure pool and whirlpool, which utilized UV treatment, were studied.
\end{abstract}

Methods: Hach Pocket Colorimeter 2 Analysis System which used a DPD method of analysis was used to determine concentrations of free chlorine and total chlorines. Concentrations of chloramines were calculated by subtracting the concentration of free chlorine from total chlorine. Thirty pool water samples for each type of pool system were analyzed on random days in the afternoons of January and February, 2015. A two sample t-test was used to compare the chloramines concentrations of the whirlpools; while a Mann-Whitney $U$ test was used to compare the chloramines concentrations of the leisure pools.

Results: There was a statistically significant difference between the mean chloramines concentration of the UV-treated whirlpool and that of the ozone-treated whirlpool $(\mathrm{p}=0.00854)$. However, there was not a statistically significant difference between the mean chloramines concentration between the UV treated leisure pool and that of the ozone treated leisure pool $(\mathrm{p}=$ 0.882048).

Conclusions: It was determined that UV was more effective than ozone in reducing chloramines concentrations in indoor public whirlpools. Therefore, in order to choose a treatment that leads to the greatest reduction of health hazard posed to pool patrons, UV is preferred. Whirlpools that intend to adopt secondary treatment may consider UV.

Key words: Indoor Swimming Pool, Chloramines, UV, Ozone

\section{INTRODUCTION}

Swimming is considered a healthy aerobic physical activity that is enjoyed by people of all ages. It is associated with reduced risk of chronic illnesses and improved mental health (Centers for Disease Control and Prevention, 2013). Over the past three 
decades, attendances of swimming pools have been increasing world-wide (Florentin, Hautemaniere, \& Philippe, 2011). However, attending swimming pools has its concerns due to the presence of physical, chemical and biological hazards. Accidents may induce physical injury to patrons, whereas chemical and biological hazards may cause illnesses to develop. To eliminate biological hazards, specifically microbiological pathogens, swimming pools are required to be disinfected with appropriate chemicals at specific concentrations. The Public Health Act and the B.C. Pool Regulation explicitly states the chemical parameters that should be adhered by all B.C. public pools. Nevertheless, disinfection has been shown to create problems in pools as certain disinfectants react with contaminants in the water and produce undesirable disinfection by-products (DBPs). An illustration of this is the reaction between chlorine, a common disinfectant, and contaminants which results in the formation of chloramines. When exposed to chloramines or DBPs in general, pool patrons may be at an elevated risk of suffering adverse health effects. To reduce the health hazard posed to the public, secondary treatments such as ozone and UV are methods employed to eliminate DBPs. In addition, secondary treatments are able to kill or inactivate pathogens, such as Cryptosporidium and Giardia, which are otherwise resistant to chlorine disinfection.

\section{LITERATURE REVIEW}

The need for proper disinfection. When a pool is in operation, contaminants are constantly being introduced. They may come from the environment, such as windblown algal spores or leaves, or from pool patrons. The majority of the contaminants found in indoor pools come from pool patrons. They include illness-causing pathogens that are expelled via accidental fecal release (AFR) or vomiting. Other contaminants may be organic or nitrogenous, and include mucus, saliva, skin, cosmetics, sweat, urea, and suntan oil (Florentin, Hautemaniere, \& Philippe, 2011). It was found that the greatest contaminant being added by swimmers is urea (Florentin, Hautemaniere, \& Philippe, 2011). As patrons spend extended periods of time submersed in the water, they are at risk of contracting illnesses that are spread by it. These illnesses, known as "recreational water illnesses" (RWI), can be gastrointestinal, non-gastrointestinal or respiratory. The main type of RWI is gastrointestinal in the form of diarrhea, and is most commonly caused by E.coli O157:H7, Cryptosporidium, Giardia, Shigella and Norovirus (World Health Organization, 2006). Of these pathogens, Giardia and Cryptosporidium are resistant to chlorine disinfection and have low infectious doses. They are especially hazardous to people with weakened immune systems as they may suffer more severe symptoms that could last long enough to be life-threatening (World Health Organization, 2006). Non-gastrointestinal and respiratory illnesses can also greatly affect the health of pool patrons. One example is the disease legionellosis, which potentially leads to respiratory failure or even death (World Health Organization, 2014). The disease is caused by the bacterium Legionella pneumophilia, which is commonly found in whirlpools that are poorly maintained (World Health Organization, 2014).

Using chlorine as a disinfectant. Due to the presence of disease-causing pathogens and the water's ability to transmit diseases from one person to another, pool water chemistry must be properly maintained to lower the potential health hazards. To do so, disinfectants are used to kill or inactivate pathogens as well as oxidize contaminants. Chlorine is the most common disinfectant used in pools due to its strong oxidizing 
property and low cost (Nemery, Hoet, \& Nowak, 2002). It is available in many forms, such as chlorine gas, liquid sodium hypochlorite, solid calcium hypochlorite (Davis, 1985). Chlorine disinfectants are popular also because they leave a "residual effect", which is the ability for it to remain stable and maintain a concentration in the water for extended durations (National Swimming Pool Foundation, 2014). It is a beneficial effect as it acts as a safeguard against pathogens and contaminants for a long period of time.

When chlorine is added to water as a disinfectant, it works in the form of free chlorine. Free chlorine is the active available chlorine in the water that is able to oxidize pathogens. The minimum concentration of free chlorine required in public swimming pools in B.C. is $0.5 \mathrm{ppm}$ for pools that are lower than 30 degrees Celsius and $1.5 \mathrm{ppm}$ for pools that are higher than 30 degrees Celsius (typically whirlpools) (Schedule 3, B.C. Pool Regulation).

Chloramines as disinfection by-product. As mentioned in the previous section, pathogenic, organic, and nitrogenous contaminants are found in pool water. While chlorine kills or inactivates pathogens, it also reacts with organic and nitrogenous contaminants (Cassan, Mercier, Castex, \& Rambaud, 2006). This depletes free chlorine and produces undesirable chemicals known as disinfection by-products (DBPs) (Cassan, Mercier, Castex, \& Rambaud, 2006). Combined chorines, or chloramines, are the most common type of disinfection byproduct. They can be either organic or inorganic. Organic chloramines are produced when chlorine reacts with organic nitrogen compounds, whereas inorganic chloramines are produced when chlorine reacts with nitrogenous substances. Chloramines are undesirable for the reason that they are much weaker than chlorine as a disinfectant. The World Health Organization states that chloramines (in the form of monochloramines) are about 2000 and 100,000 times less effective than free chlorine for the inactivation of E.coli and rotaviruses, respectively (World Health Organization, 2006). As well, chloramines are shown to cause an array of adverse health effects in humans. They may enter human body via different exposure routes, namely inhalation, ingestion and dermal contact (National Swimming Pool Foundation, 2014). At low levels, chloramines are odourous and pungent and may affect pool patrons' overall swimming experience (Nemery, Hoet, \& Nowak, 2002). At high levels or after prolonged exposure, chloramines may cause eye, nasal and throat irritation (Kaydos-Daniels, Beach, Shwe, Magri, \& Bixler, 2008) (Thickett, McCoach, Gerber, Sadhra, \& Burge, 2002). They also cause dermatitis upon contact (KaydosDaniels, Beach, Shwe, Magri, \& Bixler, 2008). In the past, outbreaks of respiratory distress and skin rash due to exposure to chloramines in indoor swimming pools have occurred (Kaydos-Daniels, Beach, Shwe, Magri, \& Bixler, 2008). As well, a widescale cross-sectional study conducted in Belgium indicated that young children who visited indoor swimming pools frequently had an elevated risk of lung damage (Bernard, et al., 2003). The researchers further speculated that the rise of asthma cases in Western societies may be owing to frequent use of indoor swimming pools, though additional epidemiological studies are needed to support such claim (Bernard, et al., 2003).

Exposure to chloramines does not only affect swimmers and bathers but also the staff who work in the proximity of the pool due to the ability of chloramines to volatilize into the air. There have been studies indicating the possibility of chronic 
exposure to chloramines being the cause of occupational asthma in swimming instructors and lifeguards (Thickett, McCoach, Gerber, Sadhra, \& Burge, 2002). Therefore, it is important to maintain chloramines at low levels in order to safeguard the public, including pool patrons and pool staff, against the adverse health effects of excessive chloramines exposure.

Regulation regarding chloramines levels. Section 10(2) $(\mathrm{g})$ of the B.C. Pool Regulation (B.C. Reg 296/2010), which is pursuant to the Public Health Act, states that the maximum permitted combined chlorine concentration in swimming pools is $1 \mathrm{ppm}$. Chloramines are a type of combined chlorine; therefore it should be kept below this limit. Section 10(2)(g) of the B.C. Pool Regulation also states that water testing at a minimum of two times per day should be conducted. In order to obtain accurate readings of chloramines concentration, it is important for pools to use a test kit that differentiates between free chlorine and combined chlorine. The B.C. Guidelines for Pool Operations recommend using test kits that use the N, N-diethyl- $p$ phenylenediamine (DPD) method instead of the orthotolidine (OTO) method (Ministry of Health Health Protection Branch, 2014). This is because OTO only indicates total chlorine concentrations and does not differentiate between free and combined chlorine (Ministry of Health Health Protection Branch, 2014).

\section{Secondary Treatment}

Importance. Secondary treatments are shown to provide added benefits to the maintenance systems of pools due to various reasons. First, they kill or inactivate pathogens that are resistant to chlorine (Hamil, 2014). Hence, they aid in reducing the number of RWIs that are caused by chlorine-resistant pathogens. Second, they reduce the overall demand for primary disinfectants (Nemery, Hoet, \& Nowak, 2002). Primary disinfectants, such as chlorine or bromine, are typically chemicals that are toxic at high levels. Safe handling and transportation of such require staffs that are well-trained. Therefore, it is safer when less primary disinfectants are required. Third, secondary treatments reduce DBPs. As a result, the health hazard of DBPs is reduced.

$\boldsymbol{U} \boldsymbol{V}$ treatment. UV treatment of pool water was found to be effective in increasing free chlorine levels and reducing chloramines levels (Cassan, Mercier, Castex, \& Rambaud, 2006). This is beneficial to pools as it reduces the amount of chlorine that is normally required in the pool to reach the same level of disinfection. It also reduces the amount of undesirable chloramines in the pool, thereby reducing the public's exposure to its hazardous effects. Additionally, UV irradiation is effective in inactivating Giardia cysts and Cryptosporidium oocysts. This is normally not accomplished when chlorine is used as the sole disinfection method. To inactivate the said (oo)cysts, the UV intensity that is required is quite low: UV exposure of 10 $\mathrm{mJ} / \mathrm{cm}^{2}$ is needed to inactivate $99.9 \%$ of Cryptosporidium oocysts, while $5 \mathrm{~mJ} / \mathrm{cm}^{2}$ is needed to inactivate $99 \%$ of Giardia cysts (World Health Organization, 2006).

The downside of using UV irradiation is that it does not create a "residual" in water, meaning its effects are not sustained in the pool water once treated water leaves the UV source. This is disadvantageous as contaminants are continually being introduced into the water, and the lack of a residual effect could mean that pool patrons may not be fully protected at all times (Cassan, Mercier, Castex, \& Rambaud, 2006). This signifies the need for UV to be used in combination with chlorine (Ministry of Health Health Protection Branch, 2014). 
In addition, the efficacy of UV is impaired when water turbidity is high due to elevated levels of particulate matter, or when biofilms have grown on the UV lamps. To solve this issue, water must be adequately filtered before it is irradiated with UV, and UV lamps must be cleaned periodically to reduce biofilm growth (World Health Organization, 2006). In terms of maintenance, the UV system composes of consumables that require periodic replacing. Specifically, mercury vapour lamps need to be replaced every three to twelve months (Hamil, 2014).

Ozone treatment. Ozone treatment is capable of inactivating Giardia cysts and Cryptosporidium oocysts. The reaction takes place very quickly, with $99.99 \%$ of Cryptosporidium oocysts being killed and $90 \%$ of Giardia cysts being inactivated after 1 minute of treatment (World Health Organization, 2006). In addition to that, ozone is able to oxidize the precursors of chloramines as well as chloramines themselves (Hamil, 2014) (World Health Organization, 2006). An added benefit of ozone treatment is that, contrary to UV treatment, ozone treatment is not affected by the turbidity of the water (Hamil, 2014). In turbid water, ozone acts as micro-flocculent and helps to improve water clarity by clumping suspended material together (Hamil, 2014). In terms of cost, although the set-up cost of ozone treatment is more expensive than UV, the long-term cost needed to run the system is lower due to the fact that no consumables are used (Hamil, 2014).

Similar to UV treatment, the downside of ozone treatment is that it does not create a "residual" effect. This means that ozone treatment must be used in conjunction with chlorine. Furthermore, the relatively high set-up cost may deter small pools that are under a tight financial budget from using it.
In terms of safety, ozone is heavier than air and is considered hazardous to humans as excessive exposure can lead to discomfort (World Health Organization, 2006). Adequate staff training is essential to ensure safe handling.

Role of Environmental Health Officers. A pool with balanced pool chemistry can help keep chloramines levels low. It also enables patrons to enjoy a pleasant swimming experience and prevents them from contracting RWIs. Moreover, it provides protection to lifeguards or other staff who work within the vicinity of the pool as they may be exposed to chloramines in the air. Although it is the responsibility of each pool operator to maintain optimal pool chemistry, Environmental Health Officers (EHOs) play very vital roles as they provide guidance and assistance on pool operations. They also ensure pool compliance to the Public Health Act and B.C. Pool Regulation. Sections 23, 24 and 25 of the Public Health Act describe the inspection power given to EHOs. As part of their inspections, EHOs monitor whether chloramines concentrations are kept under 1 ppm as prescribed by the Act. The ultimate goal of EHOs is to protect public health by identifying health hazards and prescribing actions that can mitigate adverse health effects.

Research Question. There is a lack of evidence indicating whether one particular type of secondary treatment is more effective at reducing chloramines levels in indoor pools than the others. For the purpose of this study, UV and ozone treatments were examined to investigate whether there was a significant difference in their effectiveness in reducing chloramines.

With regards to whirlpools, the following null $\left(\mathrm{H}_{0}\right)$ and alternate $\left(\mathrm{H}_{1}\right)$ hypotheses were established: 
1) $\mathrm{H}_{0}$ : There is no difference between the mean chloramines concentration of the UV treated whirlpool and the ozone treated whirlpool $(\mu 1=\mu 2)$

2) $\mathrm{H}_{1}$ : There is a difference between the mean chloramines concentration of the UV treated whirlpool and the ozone treated whirlpool $(\mu 1-\mu 2 \neq 0)$

With regards to leisure pools, the following null $\left(\mathrm{H}_{0}\right)$ and alternate $\left(\mathrm{H}_{1}\right)$ hypotheses were established:

1) $\mathrm{H}_{0}$ : There is no difference between the mean chloramines concentration of the UV treated leisure pool and the ozone treated leisure pool $(\mu 3=\mu 4)$

2) $\mathrm{H}_{1}$ : There is a difference between the mean chloramines concentration of the UV treated leisure pool and the ozone treated leisure pool $(\mu 3-\mu 4 \neq 0)$

\section{MATERIALS AND METHODS}

To compare the difference in chloramines concentrations in pools treated by UV versus ozone, water from two public swimming pools were sampled and measured: Hillcrest public swimming pool and Killarney public swimming pool. Hillcrest public swimming pool in Burnaby B.C. utilized UV for its leisure pool and whirlpool as secondary disinfection on top of chlorine disinfection. The volumes of its leisure pool and whirlpool were 115,000 US gallons and 15,450 US gallons, respectively. The bather loads of the leisure pool and the whirlpool were approximately 215 and 165 per day, respectively (Healy. S, personal communication, January 15, 2015). Killarney public swimming pool in Vancouver, B.C. utilized ozone for its leisure pool and whirlpool as secondary disinfection on top of chlorine disinfection. Its leisure pool and whirlpool had volumes of 75,000 US gallons and 6000 US gallons, respectively. The bather load was approximately 1000 patrons per day, although this figure does not exclusively represent the number of people who used the leisure pool and whirlpool but also included those that used the main pool (Healy. S, personal communication, January 15, 2015).

Chloramines concentrations were determined by using the Hach Pocket Colorimeter 2 Analysis System (Catalog \#59571-88), which is a hand-held device that produced digital readings of total chlorine and free chlorine concentrations of the water being sampled. Concentrations of chloramines were then calculated by subtracting free chlorine concentrations from total chlorine concentrations (Bessonneau, Derbez, Clement, \& Thomas, 2011). The Analysis System operated using the DPD (N, N-diethyl-p-phenylenediamine) colorimetric method. It required sample cells, DPD Free Chlorine powder pillows, DPD Total Chlorine powder pillows, and DPDChlorine HR Spec Check Secondary Standards Kit.

Water sampling and measuring were conducted on random days between $2 \mathrm{pm}$ to $5 \mathrm{pm}$ in January and February, 2015. A total of 30 samples were taken per pool (leisure pool and whirlpool, respectively) at each of the two pool locations (Hillcrest Pool and Killarney Pool) for a total of 120 samples. Water was sampled 18 inches deep in the pool, away from any return inlets or pool patrons. Measurements were made on-site as soon as the water was collected to avoid volatilization of chlorine from the water into the air, which could have resulted in an under-representation of chlorine concentrations.

Reliability. To ensure that the measured results were reliable, the study was administered by the same researcher using the same equipment consistently. The sampling and measurement protocols were 
strictly followed so that each sample was measured in the same manner: water was sampled up to the $5 \mathrm{~mL}$ fill line of the sample cell and the same amounts of reagents were added each time as they were in individually pre-packaged pillows. The sampling and measurement instructions as well as the equipment were supplied directly by Hach Company, which resulted in a high user replication. In addition, since the instrument produced a digital reading on the screen to indicate the concentrations of different chemicals, the results were objective and no subjective judgments by the researcher were involved.

In terms of the instrument's reliability, the precision of the data was $\pm 0.2 \mathrm{ppm} \mathrm{Cl}_{2}$, based on a $95 \%$ confidence interval (Hach Company, 2003).

Validity. The estimated detection limit of the Hach Pocket Colorimeter 2 Analysis System was 0.1 ppm $\mathrm{Cl}_{2}$ (Hach Company, 2003). The instrument was factory calibrated with a calibration curve saved in the instrument. Prior to each sampling session, the "DPDChlorine HR Spec Check Secondary Standards Kit" was used to check if the instrument was making accurate measurements. Furthermore, content validity was increased as the device produced the concentrations of free and total chlorine, which made it an easy calculation to determine the concentrations of chloramines.

Internal validity of the study was quite high as the same instruments were used consistently. The methods were clearly laid out and strictly followed. With respect to external validity, the results of the study are only generalizable to other indoor public swimming pools that utilize UV or ozone for secondary treatment and have similar pool volumes and bather loads.

Inclusion and Exclusion Criteria. Included were the Killarney public leisure pool and whirlpool in Burnaby, B.C. and the Hillcrest public leisure pool and whirlpool in Vancouver, B.C. Also, included was the DPD method using the Hach Pocket Colorimeter 2 Analysis System photometer to determine the concentrations of total chlorine as well as free chlorine.

Excluded were other public leisure pools and whirlpools in Vancouver and Burnaby, B.C. Also, excluded were the amperometric titration and the colorimetric colour matching method of DPD.

\section{STATISTICAL ANALYSIS}

Description of the type of data. Since concentrations of free chlorine and total chlorine were measured, the data was considered numerical, on a continuous scale (Heacock \& Sidhu, Module 5: Descriptive Statistics, 2014). The data was measured to the precision of one decimal point. To calculate the concentrations of chloramines, which was the chemical of interest of this study, the free chlorine concentrations were subtracted from the total chlorine concentrations.

Statistical Package used. Microsoft Excel (Microsoft Corporation, 2010) was used to analyze descriptive statistics. NCSS Version 9.0 was used to analyze inferential statistics (Hintze, 2015).

Descriptive Statistics. With regards to whirlpools, from Table 1, it was found that the mean, median, range and standard deviation of chloramines concentrations were higher for the UV-treated whirlpool than the ozone-treated whirlpool.

With regards to leisure pools, it was found that the mean, median and standard deviation of chloramines concentrations were higher for the ozone-treated leisure pool than the UV-treated leisure pool. The range was identical for both pools. 
Table 1. Descriptive statistics for the chloramines concentrations in UV treated and ozone treated whirlpools and leisure pools

\begin{tabular}{|l||c|c||c|c|}
\hline & $\begin{array}{c}\text { Killarney Pool: } \\
\text { UV treated } \\
\text { Whirlpool }\end{array}$ & $\begin{array}{c}\text { Hillcrest Pool: } \\
\text { Ozone treated } \\
\text { Whirlpool }\end{array}$ & $\begin{array}{c}\text { Killarney Pool: } \\
\text { UV treated } \\
\text { Leisure Pool }\end{array}$ & $\begin{array}{c}\text { Hillcrest Pool: } \\
\text { Ozone treated } \\
\text { Leisure Pool }\end{array}$ \\
\hline \hline Sample size & 30 & 30 & 30 & 30 \\
\hline Mean $(\mathrm{ppm})$ & 1.38 & 1.1 & 1.13 & 1.14 \\
\hline Median $(\mathrm{ppm})$ & 1.3 & 1.05 & 1.05 & 1.3 \\
\hline Range & 1.9 & 1.4 & 1.4 & 1.4 \\
\hline $\begin{array}{l}\text { Standard } \\
\text { Deviation }\end{array}$ & 0.41 & 0.39 & 0.39 & 0.43 \\
\hline
\end{tabular}

Inferential Statistics. Based on the data collected, there were two independent groups being tested. The first group contrasted the difference between mean chloramines concentrations measured in a UV treated whirlpool to the mean chloramines concentrations measured in an ozone treated whirlpool. The second group contrasted the difference between mean chloramines concentrations measured in a UV treated whirlpool to the mean chloramines concentrations measured in an ozone treated whirlpool. Two-sample twotailed T-tests were performed as there was no prior scientific knowledge of which disinfection method is more effective at reducing chloramines concentrations (Heacock \& Sidhu, Module 5: Inferential Statistics, 2014).

\section{RESULTS}

\section{Interpretation of Whirlpool Data}

In the two-sample two-tailed T-test, based on the results of the Test of Assumptions, normality was not rejected. Equal variances were also not rejected. This shows that the data was normally distributed with equal variances. Therefore, results from the EqualVariance T-test can be interpreted (Heacock \& Sidhu, Module 5: Inferential Statistics, 2014).
Probability, $\mathrm{p}=0.05$ (or $5 \%$ ), was used as a significance level to evaluate statistical significance. If $\mathrm{p}<0.05$, the null hypothesis would be rejected and it would be concluded that the there was a statistically significance difference between the mean concentrations of the two samples. Under the EqualVariance T-test, as $\mathrm{p}=0.00854$, the null hypothesis was rejected and the alternative hypothesis was accepted. This meant that there was a statistically significant difference between the mean chloramines concentration of the two whirlpools, where the mean chloramines concentration of the UV-treated whirlpool was lower than that of the ozone-treated whirlpool.

The power of the test was 0.76343 (or 76\%) at $\alpha=0.05$. The power was slightly lower than $80 \%$. This indicates that although there was a statistically significant difference in chloramines concentration between UV treated whirlpools and ozone treated whirlpools, chance may have played a role in the findings.

\section{Interpretation of Leisure Pool Data}

In the two sample two-tailed T-test, based on the results of the Test of Assumptions, normality was rejected. Equal variances were not rejected. This showed that the data was not normally distributed with equal variances. Therefore, interpretations of 
results were made from the Mann-Whitney $\mathrm{U}$ or Wilcoxon Rank-sum non-parametric test results (Heacock \& Sidhu, Module 5: Inferential Statistics, 2014).

Under the Mann-Whitney U or Wilcoxon Rank-sum non-parametric test results, the null hypothesis was not rejected as $\mathrm{p}=0.882048$, which is higher than $\mathrm{p}=0.05$. This means that there was not a statistically significant difference between the mean chloramines concentration between the UV treated leisure pool and that of the ozone treated leisure pool.

\section{DISCUSSION}

From the results, it was determined that there was a statistically significant difference in the level of chloramines that were measured between pools that used UV and ozone as their secondary treatment. Specifically, it was found that UV treatment was more effective in reducing chloramines than ozone in whirlpools. However, the same pattern was not noticed in leisure pools.

Due to the lack of literature available, it was difficult to refer the results of this study to any previous research done in order to make meaningful comparisons. It is well established that UV and ozone treatment provide added benefits to pool disinfection due to their ability to kill or inactivate pathogens that are resistant to chlorine disinfection (National Swimming Pool Foundation, 2014). However, there is very limited information on their respective effectiveness in chloramines reduction. From a study conducted by a previous BCIT student Emily Ho (2008), it was found that pools that used UV treatment on top of chlorine disinfection had significantly lower levels of chloramines than pools that used chlorine only. Another study showed that ozone treatment did not create a statistically significant difference in chloramines reduction in pools (Mah, 2014). By integrating the results from those two studies with this current one, it could be inferred that using UV as a secondary treatment method is beneficial, and it is more beneficial to use UV than ozone on whirlpools as it is able to reduce chloramines more effectively.

Based on the design and background of this study, some speculations were made to explain the research results. Killarney Pool, which is the only pool in Vancouver that utilizes ozone treatment, was closed for three to four weeks in December, 2014 for their annual maintenance. After the pool reopened at the end of December and data were collected in January and February, 2015, the researcher found out that the pool had trouble with their ozone generators and that occasionally only one of the two were working (Chesterson, S, personal communication, March 5, 2015). While it was hard to determine whether having one less functioning ozone generator to produce ozone affected the level of chloramines being measured, the fact that there were problems with operating the ozone generator signified the complexity of ozone systems in general. They require more maintenance than UV systems (Hamil, 2014).

As stated in the literature review, ozone and UV treatment systems each have their advantages and disadvantages. While both treatments are active against pathogens that are resistant to chlorine disinfection, ozone treatment is preferred over UV in situations where the incoming source water is turbid and that filtration is inadequate to reduce the turbidity to a level for UV treatment to function effectively. However, if water turbidity is not an issue, then there is more overall advantage to use UV treatment rather than ozone. This is because UV treatment does not involve the use of hazardous chemicals, does not require high level 
maintenance, and is more effective in reducing chloramines in whirlpools as shown in this study. This information is important for pool operators as elevated chloramines constitute a public health hazard. Pool operators are responsible for choosing a treatment method that is best suited for their whirlpool in order to achieve effective chloramines reduction. Moreover, pool operators should have adequate knowledge in how to troubleshoot either the UV or ozone system to minimize the health impact that a system failure has to the general public. When a secondary treatment system fails, chloramines level may increase to a level that leads to adverse health effects such as skin rash, mucosal irritation and exacerbation of asthma. The concentration of pathogens such as Giardia and Cryptosporidium may also increase, thereby increasing the general public's likelihood in contracting a RWI. Additionally, it is the responsibility of the pool operator to ensure that the chloramines level is kept below 1 ppm at all times. EHOs have the authority to inspect a pool to verify whether pools are in compliance.

In terms of leisure pools, this study has shown that neither UV nor ozone performed better than the other in terms of chloramines reduction. Since the operating cost of ozone in the long run is cheaper than UV due to the lack of consumables being used, pool operators may choose to use ozone treatment to save costs, given that water turbidity is not an issue. This decision should only be made after considering other factors such as filtration rate, flow rate, availability of trained staff etc. Ultimately, the decision as to which treatment method to choose is dependent on multiple factors and pool operators should inquire different professionals such as engineers as well as EHOs to seek further information.
The impact that this study has on EHOs lie in two main areas. When EHOs review pool plans for whirlpools, they may suggest to pool operators to use UV treatment rather than ozone for optimal chloramines reduction. As well, during a pool inspection, EHOs should be aware that ozone treated whirlpools are more likely to have higher levels of chloramines, or that the system is more likely to malfunction, than UV treated whirlpools. If chloramines level exceeds 1 ppm, EHOs may make recommendations such as shock chlorinating the pool, installing a UV treatment system, increasing flow rate etc.

\section{RECOMMENDATIONS}

It is important for a pool to understand the strengths and weaknesses of different secondary treatment systems to choose one best suited for the pool. For whirlpools, it is recommended that UV treatment be used rather than ozone in order to reduce chloramines more effectively. For leisure pools, more research is needed to determine whether there is any difference in the two treatments in terms of chloramines reduction.

\section{LIMITATIONS}

There were a number of limitations that were present in the study design.

First, the volumes of the pools being studied were different. Hillcrest's whirlpool and leisure pool were 2.5 and 1.5 times bigger than those of Killarney, respectively. This could have had an effect on how the disinfectants as well as the contaminants were distributed in the pools during the time when the water was sampled. The bather loads of the two pools were also different. For the purpose of this study, it would have been more meaningful to draw conclusions from pools that had similar pool volumes and bather loads. In addition, the study could have been improved by sampling 
multiple UV treated and ozone treated pools rather than just studying one UV treated and one ozone treated pool. However, due to the fact that Killarney was the only pool in Vancouver that utilizes ozone, and that geographical and financial constraints restricted the researcher from using a pool that is outside of Vancouver, this limitation was unavoidable.

Second, as discussed in the previous section, one of the ozone generators at Killarney Pool was not functioning when the water was sampled. This could have been one of the contributing factors as to the reason why chloramines reduction by ozone was found to be less effective than UV. Therefore, it would have been ideal to choose a time when the ozone system was working as a whole in order to compare its peak performance to that of UV.

Third, the testing equipment was only moderately reliable. Occasionally, it would yield results that were either very low (e.g. 0 ppm of free chlorine) or very high (e.g. 5 ppm of free chlorine). When this occurred, the sample would have to be discarded for resampling to occur.

Fourth, it was logistically difficult to collect many samples from each of the four pools within a tight time frame (January and first week of February). Due to that, the sample size of the study was rather small (thirty samples per pool), and this could have had an impact on the power of the statistical analysis.

\section{FUTURE STUDIES}

1. Conduct the same study but use multiple pools instead of one ozone treated and one UV treated pool. This should be done with adequate planning as it may take a long time to acquire permission to gain access to that many pools.
2. As ozone generators are more difficult to maintain, it is interesting to understand how different ozonetreated pools compare to each other in terms of chloramines level. A suggestion is to conduct a study between different ozone treated pools, such as between Killarney Pool and West Vancouver Aquatic Centre, to determine whether there is any significant difference between their chloramines concentration.

3. Some pools conduct their water testing in the mechanics room, where there are valves connected to different water sources (for example, one for leisure pool, one for whirlpool) for pool mechanics to use to determine chloramines concentration. Some other pools conduct their water testing using the same method as this study, 18 inches deep into the water, at the pool. A research suggestion is to investigate whether there is a difference in chloramines readings when water is sampled in those two locations.

\section{CONCLUSIONS}

UV and ozone treatments are used in indoor public swimming pools to assist chlorine in achieving a higher level of disinfection. They serve important functions in killing or eliminating pathogens that are resistant to chlorine disinfection, as well as reducing undesirable disinfection byproducts in the form of chloramines that are produced when chlorine reacts with contaminants in the water.

It was determined from this study that UV treatment was more effective than ozone in reducing chloramines concentrations in whirlpool. It was also determined that there was no difference in the effectiveness of the 
two treatments in reducing chloramines concentrations in leisure pools. When deciding what type of secondary treatment to use, EHOs as well as pool managers must keep public health in mind and choose a treatment that can provide the greatest protection to pool patrons. Whirlpools are recommended to be treated with UV in order for chloramines level to be kept low.

\section{ACKNOWLEDGEMENTS}

I would like to extend my appreciation to my supervisor, Bobby Sidhu, for his encouragement and support. Thanks to all the staff from Vancouver Board of Parks and Recreation for being extremely helpful and accommodating, especially Sean Healy, Peter Fox and Eaman McGinley.

\section{COMPETING INTEREST}

The authors declare that they have no competing interests.

\section{REFERENCES}

Bernard, A., Carbonnelle, S., Michel, O., Higuet, S., De Burbure, C., Buchet, J. P., . . . Doyle, I. (2003). Lung hyperpermeability and asthma prevalence in schoolchildren: unexpected associations with the attendance at indoor chlorinated swimming pools. Occupational and Environmental Medicine, 60(6), 385394.

Bessonneau, V., Derbez, M., Clement, M., \& Thomas, O. (2011). Determinants of chlorination by-products in indoor swimming pools. International Journal of Hygiene and Environmental Health, 215, 76-85.
Blatchley III, E. R., \& Li, J. (2009). UV photodegradation of inorganic chloramines. Environmental Science and Technology, 43, 60-85.

Caldwell, G. G., Lindsey, N. J., Wulff, H., Donnelly , D. D., \& Bohl, F. N. (1974). Epidemic with adenovirus type 7 acute conjunctivitis in swimmers. American Journal of Epidemiology, 99, 230-234.

Cassan, D., Mercier, B., Castex, F., \& Rambaud, A. (2006). Effects of medium-pressure UV lamps radiation on water quality in a chlorinated indoor swimming pool. Chemosphere, 62, 1507-1513.

Centers for Disease Control and Prevention. (2013, March 6). Healthy Swimming / Recreational Water. Retrieved from http://www.cdc.gov/healthywater/sw imming/health_benefits_water_exerc ise.html

Chan, I. (2015) BCIT Environmental Health Journal.

Davis, B. J. (1985, October). Whirlpool operation and the prevention of infection. Infection Control, 6(10), 394-397.

Florentin, A., Hautemaniere, A., \& Philippe, H. (2011). Health effects of disinfection by-products in chlorinated swimming pools. International Journal of Hygiene and Environmental Health, 214(6), 461469. 
Hach Company. (2003). Pocket Colorimeter II analysis system instruction manual. USA: Hach Company.

Hamil, B. (2014, August). Secondary disinfection for public swimming venues: ozone versus UV. Water Conditioning \& Purification.

Heacock, H., \& Sidhu, B. (2014). Module 5: Descriptive Statistics. In ENVH8400 Course Manual. Burnaby, BC: British Columbia Institute of Technology.

Heacock, H., \& Sidhu, B. (2014). Module 5: Inferential Statistics. ENVH8400 Research Methods Course Manual. Burnaby: British Columbia Institute of Technology.

Ho, E. (2008). Concentration of chloramines in chlorinated vs UV pools. (Unpublished research project). British Columbia Institute of Technology, Burnaby, BC, Canada.

Hintze, J. (2015). NCSS 9. Kaysville, Utah, USA. Retrieved from NCSS, LLC: www.ncss.com

Kaydos-Daniels, C., Beach, M. J., Shwe, T., Magri, J., \& Bixler, D. (2008). Health effects associated with indoor swimming pools: A suspected toxic chloramine exposure. Journal of the Royal Institute of Public Health, 122, 195-200.

Keswick, B. H., Gerba, C. P., \& Goyal, S. M. (1981). Occurance of enteroviruses in community swimming pools. American Journal of Public Health, 71(9), 1026-1030.
Mah, D. (2014). The Effectiveness of Ozone-chlorine Treatment for Reducing Chloramine Concentration Compared to Chlorine Treatment in Swimming Pools and Whirlpools. Environmental Health Journal 2014.

Ministry of Health Health Protection Branch. (2014). B.C. Guidelines for Pool Operations. Retrieved from http://www.health.gov.bc.ca/protect/ pdf/pool_operations_guidelines_jan2 014_final.pdf

National Swimming Pool Foundation. (2014). Pool and Spa Operator Handbook. Colorado Springs: National Swimming Pool Foundation.

Nemery, B., Hoet, P. H., \& Nowak, D. (2002). Indoor swimming pools, water chlorination and respiratory health. European Respiratory Journal, 19, 790-793.

Thickett, K. M., McCoach, J. S., Gerber, J. M., Sadhra, S., \& Burge, P. S. (2002). Occupational asthma caused by chloramines in indoor swimmingpool air. European Respiratory Journal, 19, 827-832.

World Health Organization. (2006). Guidelines for Safe Recreational Water Environments Volume 2 Swimming Pools and Similar Environments. Geneva: WHO Press.

World Health Organization. (2014, November). Legionellosis. Retrieved from Fact Sheet Number 285: http://www.who.int/mediacentre/fact sheets/fs285/en/ 